\title{
Randomized, Double-Blind Comparison of Tenofovir Alafenamide (TAF) vs Tenofovir Disoproxil Fumarate (TDF), Each Coformulated With Elvitegravir, Cobicistat, and Emtricitabine (E/C/F) for Initial HIV-1 Treatment: Week 144 Results
}

\author{
José R. Arribas, MD, PhD, * Melanie Thompson, MD, $†$ Paul E. Sax, MD, $\ddagger$ Bernhard Haas, MD, $\S$ \\ Cheryl McDonald, MD, \| David A. Wohl, MD, $\mid$ Edwin DeJesus, MD,\# Amanda E. Clarke, MD,** \\ Susan Guo, PhD, $\dagger+$ Hui Wang, PhD, $\dagger \dagger$ Christian Callebaut, PhD, $\dagger \dagger$ Andrew Plummer, BS, $\dagger \dagger$ \\ Andrew Cheng, MD, PhD, $\dagger$ - Moupali Das, MD, MPH, $\dagger+$ and Scott McCallister, MD $\dagger \dagger$
}

\begin{abstract}
In 2 double-blind phase 3 trials, 1733 antiretroviralnaive adults were randomized to tenofovir alafenamide (TAF) or tenofovir disoproxil fumarate (TDF), each coformulated with elvitegravir/cobicistat/emtricitabine (E/C/F). At 144 weeks, TAF was superior to TDF in virologic efficacy, with $84.2 \% \mathrm{vs}$ $80.0 \%$ having HIV-1 RNA $<50$ copies $/ \mathrm{mL}$ (difference $4.2 \%$; 95\% confidence interval: $0.6 \%$ to $7.8 \%$ ). TAF had less impact than TDF on bone mineral density and renal biomarkers. No participants on TAF had renal-related discontinuations vs 12 on TDF $(P<0.001)$, with no cases of proximal tubulopathy for TAF vs 4 for TDF. There were greater increases in lipids with TAF vs TDF, with no difference in the total cholesterol to high-density lipoprotein ratio. For initial HIV therapy, $\mathrm{E} / \mathrm{C} / \mathrm{F} / \mathrm{TAF}$ is superior to $\mathrm{E} / \mathrm{C} / \mathrm{F} / \mathrm{TDF}$ in efficacy and bone and renal safety.
\end{abstract}

Key Words: tenofovir alafenamide, integrase inhibitor, randomized controlled trial, HIV, bone mineral density, renal safety

(J Acquir Immune Defic Syndr 2017;75:211-218)

\section{INTRODUCTION}

Use of tenofovir disoproxil fumarate (TDF)-based regimens is highly effective but may be associated with renal and bone toxicity, attributed to high circulating plasma levels of tenofovir (TFV). ${ }^{1-5}$ By contrast, use of tenofovir alafenamide (TAF)-based regimens has less impact on measures of renal and bone safety, attributed to significantly lower plasma TFV levels while increasing delivery of intracellular TFV-diphosphate, the active moiety of both compounds. ${ }^{6}$

Received for publication October 27, 2016; accepted January 11, 2017

From the *Infectious Diseases Unit, Internal Medicine Service, Hospital Universitario La Paz, Madrid, ES; †AIDS Research Consortium of Atlanta, Atlanta, GA; $\ddagger$ Division of Infectious Diseases, Brigham and Women’s Hospital, Boston, MA; §Internal Medicine, General Hospital Graz-West, Graz, AT; ||Tarrant County Infectious Disease Associates, Fort Worth, TX; 9 Division of Infectious Diseases, UNC School of Medicine, Chapel Hill, NC; \#Orlando Immunology Center, Orlando, FL; **Claude Nicol Centre, Royal Sussex County Hospital, Brighton \& Sussex University Hospitals NHS Trust, Brighton, United Kingdom; and †DDepartments of Biometrics, Virology, Clinical Operations, and HIV Clinical Research, Gilead Sciences, Inc., Foster City, CA.

This study was sponsored by Gilead Sciences, Inc. (Gilead). J.R.A. has received personal fees from Gilead Sciences (Gilead), ViiV, Janssen Therapeutics (Janssen), AbbVie, Bristol-Myers Squibb (BMS), and Merck Laboratories (Merck). M.T. reports grant support to her Institution from Gilead Sciences, BMS, GeoVax, Kowa Research Institute, Merck, Pfizer, Tobira, ViiV, Janssen, and GlaxoSmithKline (GSK). P.E.S. has received research support from BMS, Gilead, GSK, and Merck; consulting fees from AbbVie, BMS, Gilead, GSK, Merck, and Janssen. B.H. reports no conflicts of interest. C.M.D. reports personal fees from BMS, Gilead, Merck, ViiV, and Janssen. D.A.W. has received research grant support from Merck and GSK and receives consulting fees from Janssen and Gilead. E.D.J. has received research grant support from Abbott Laboratories, Achillion Pharmaceuticals, Avexa, BMS, Gilead, GSK, Idenix, Janssen, Merck, Sangamo, Taimed, and Tobira and consulting fees as a member of advisory boards for Gilead and Janssen. A.E.C. has received travel grants to attend HIV conferences from Gilead, Janssen, and BMS and a research grant to institution for Gilead trials. S.G., H.W., A.P., C.C., A.C., M.D., and S.M. are employees of Gilead and hold stock interest in the company.

All authors were involved in the development of the primary manuscript, interpretation of data, have read and approved the final version, and have met the criteria for authorship as established by the ICMJE. J.R.A. enrolled participants, analyzed data and independently interpreted the results, and edited and approved the manuscript. M.T., P.E.S., B.H., C.M.D., D.A.W., E.D.J., and A.E.C. enrolled participants, reviewed and interpreted analyses of data, and edited the draft manuscript. A.P., A.C., M.D., and S.M.C. designed the study. S.G. and H.W. performed the data analyses, which were reviewed and interpreted by C.C., A.C., M.D., and S.M.C. The first draft was written by J.R.A. and S.M.C. All authors contributed to edits of the final report. Gilead Sciences (Sponsor) had a role in deciding whether or not the results would be published.

Supplemental digital content is available for this article. Direct URL citations appear in the printed text and are provided in the HTML and PDF versions of this article on the journal's Web site (www.jaids.com).

Correspondence to: José R. Arribas, MD, PhD, Infectious Diseases Unit, Internal Medicine Service, Hospital La Paz, IdiPAZ, Castellana 261, 28046 Madrid, Spain (e-mail: joser.arribas@salud.madrid.org). 
In treatment-naive individuals and those switching from TDF-containing regimens, the single-tablet coformulation of elvitegravir/cobicistat/emtricitabine/TAF (E/C/F/TAF) demonstrated high efficacy and significantly reduced effects on estimated glomerular filtration rate (eGFR), proteinuria, albuminuria, and bone mineral density (BMD) compared with TDFcontaining regimens. ${ }^{6-9}$ Treatment-naive participants in 2 large randomized, international, double-blind, placebo-controlled trials (GS-US-292-0104 and GS-US-292-0111, ClinicalTrials.gov numbers NCT01780506 and NCT01797445) who received TAF had significantly less bone demineralization in the lumbar spine and total hip and significantly lower rates of total proteinuria, albuminuria, and proximal tubular proteinuria at weeks 48 and 96 compared with those on TDF. 6,7

Given these efficacy and safety data, E/C/F/TAF has become a recommended initial regimen in the HIV treatment guidelines for the United States (U.S.) and Europe. ${ }^{10-16}$ However, the durability of virologic response and the persistence of the favorable effects of TAF compared with TDF on renal and bone safety parameters are of long-term interest because HIV-infected patients who initiate TAFcontaining regimens could anticipate receiving lifelong therapy. We present efficacy and safety data from these trials through 144 weeks of blinded treatment.

\section{METHODS}

\section{Study Design and Participants}

Details on design, inclusion criteria, and methodology of the trials have been previously reported. ${ }^{6}$ Briefly, antiretroviral treatment-naive adults were randomized 1:1 to once-daily TAF $10 \mathrm{mg}$ vs TDF $300 \mathrm{mg}$, both coformulated with elvitegravir 150 $\mathrm{mg}$, cobicistat $150 \mathrm{mg}$, and emtricitabine $200 \mathrm{mg}(\mathrm{E} / \mathrm{C} / \mathrm{F})$. The studies were approved by the U.S. Food and Drug Administration (FDA) and institutional review boards at all sites.

\section{Statistical Analysis}

Pooled analyses of week 144 data from both studies were prespecified in the protocols and analysis plans. Efficacy was assessed by examining the proportion in each group with plasma HIV-1 RNA $<50$ copies/mL at week 144 (U.S. FDA-defined snapshot algorithm). ${ }^{17}$ A 12\% margin and 2 -sided 95\% confidence interval (CI) (unadjusted alpha level) were used to establish noninferiority; once established, the same CI was prespecified for use to evaluate superiority. An identical approach was applied using a plasma HIV-1 RNA threshold of $<20$ copies/mL. Adverse events (AEs) were coded with the Medical Dictionary for Regulatory Activities (version 19.0). The Fisher exact test was used to compare differences for AEs and Wilcoxon rank-sum test to compare differences for continuous laboratory test results (SAS; version 9.2). A post hoc evaluation of proximal renal tubulopathy was performed using the following confirmed criteria: rise in serum creatinine $\geq 0.4$ $\mathrm{mg} / \mathrm{dL}$, dipstick proteinuria $\geq 2$ grade-level increase from baseline in urine protein, normoglycemic glycosuria, and a 1 grade-level change in serum hypophosphatemia.

\section{RESULTS}

A total of 1733 adults received at least 1 dose of study drug: 866 TAF and 867 TDF. Baseline characteristics were similar between groups (Table S1 http://links.lww.com/QAI/ A986), with similar rates of retention through week 144 (TAF $85 \%$ vs TDF $82 \%$ ).

At 144 weeks, $84.2 \%$ of participants receiving TAF and $80.0 \%$ receiving TDF had HIV-1 RNA $<50$ copies $/ \mathrm{mL}$ (U.S. FDA-defined snapshot algorithm) using the full analysis set (difference $4.2 \% ; 95 \%$ CI: $0.6 \%$ to $7.8 \%$ ) (Fig. 1 ). Treatment discontinuation (primarily due to AEs or withdrawal of consent, among other reasons not related to efficacy) contributed to the lower percentage of virologic success with TDF. Analyses comparing rates of virologic suppression between treatments within prespecified subgroups favored TAF over TDF at week 144 for those with baseline HIV-1 RNA $\leq 100,000$ copies $/ \mathrm{mL}$, those with baseline CD4 count $\geq 200$ cells $/ \mu \mathrm{L}$, women, adults $\geq 50$ years of age, nonblack participants, and those with an adherence rate of $\geq 95 \%$ (Figure S1 http://links.lww.com/QAI/A986). At 144 weeks, $81.1 \%$ on TAF and $75.8 \%$ on TDF had HIV-1 RNA $<20$ copies/mL (U. S. FDA-defined snapshot algorithm) (difference 5.4\%;

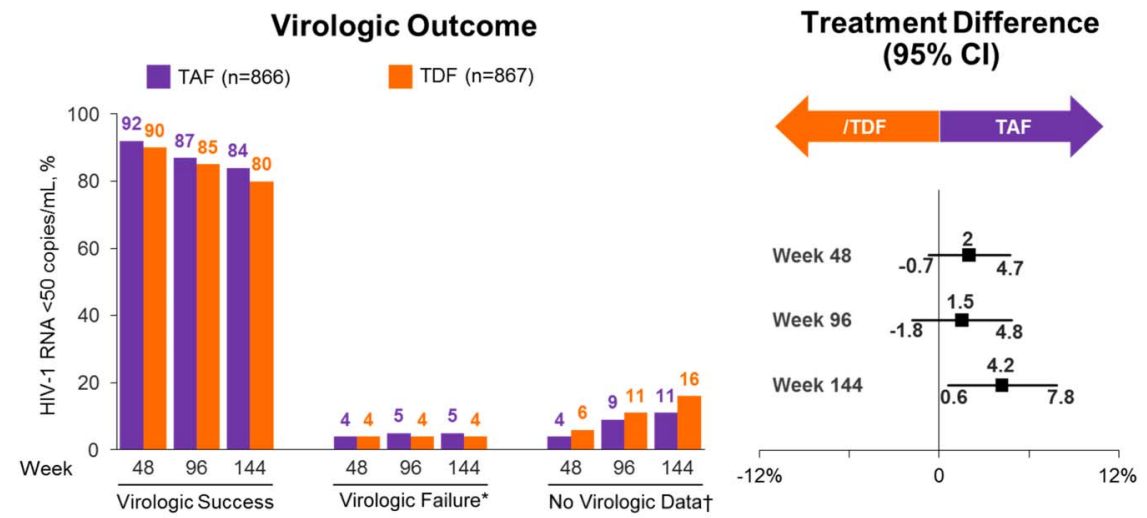

FIGURE 1. Virologic outcomes at weeks 48, 96, and 144.

\begin{tabular}{|l|c|c|}
\hline $\begin{array}{l}\text { Reasons for virologic failure and } \\
\text { no virologic data at Week } 144\end{array}$ & $\begin{array}{c}\text { TAF } \\
(\mathbf{N}=866)\end{array}$ & $\begin{array}{c}\text { TDF } \\
(\mathrm{N}=867)\end{array}$ \\
\hline${ }^{*} \mathrm{HIV}-1 \mathrm{RNA} \geq 50 \mathrm{c} / \mathrm{mL}$ & $40(4.6 \%)$ & $34(3.9 \%)$ \\
\hline $\begin{array}{l}\mathrm{HIV}-1 \mathrm{RNA} \geq 50 \mathrm{c} / \mathrm{mL} \text { in } \\
\text { Week } 144 \text { Window }\end{array}$ & $10(1.2 \%)$ & $9(1.0 \%)$ \\
\hline $\begin{array}{l}\text { Discontinued Study Drug } \\
\text { Due to Lack of Efficacy }\end{array}$ & $7(0.8 \%)$ & $8(0.9 \%)$ \\
\hline $\begin{array}{l}\text { Discontinued Study Drug } \\
\text { Due to Other Reasons and } \\
\text { Last Available HIV-1 RNA } \geq 50 \mathrm{c} / \mathrm{mL}\end{array}$ & $21(2.4 \%)$ & $15(1.7 \%)$ \\
\hline $\begin{array}{l}\text { Added New ARV } \\
\text { tNo Virologic Data in Week } 144 \mathrm{Window}\end{array}$ & $27(11.2 \%)$ & $139(16.0 \%)$ \\
\hline $\begin{array}{l}\text { Discontinued Study Drug } \\
\text { Due to AE/Death }\end{array}$ & $13(1.5 \%)$ & $29(3.3 \%)$ \\
\hline $\begin{array}{l}\text { Discontinued Study Drug Due to } \\
\text { Other Reasons } \\
\text { Last and } \\
\text { Last Available HIV-1 RNA }<50 \mathrm{c} / \mathrm{mL}\end{array}$ & $79(9.1 \%)$ & $99(11.4 \%)$ \\
\hline $\begin{array}{l}\text { Missing Data During Window but on } \\
\text { Study Drug }\end{array}$ & $5(0.6 \%)$ & $11(1.3 \%)$ \\
\hline
\end{tabular}


95\% CI: $1.5 \%$ to $9.2 \%)$. CD4 cell counts increased in both groups, with mean (SD) changes from baseline of 326 (215.3) cells $/ \mu \mathrm{L}$ for TAF and $305(204.5)$ cells $/ \mu \mathrm{L}$ for TDF $(P=0.062)$ at week 144 .

By 144 weeks, virologic failure with resistance occurred in 24 participants: $12(1.4 \%)$ on TAF vs 12 (1.4\%) on TDF. Genotypic resistance data: nucleoside reverse-transcriptase inhibitor (NRTI) and Elvitegravir $($ EVG) resistance $(n=8)$, NRTI resistance only $(n=4)$ in the TAF group; NRTI and EVG resistance $(n=7)$, NRTI resistance only $(n=4)$, EVG resistance only $(n=1)$ in the TDF group. Two participants on TAF and 4 on TDF had newly detected genotypic resistance between weeks 96 and 144. In those with genotypic resistance, there was no statistical difference in median baseline viral load between TAF and TDF (252,200 vs 115,500 HIV-1 RNA copies/mL; $P=0.270)$.

Both regimens continued to be well tolerated through week 144, with similar rates of drug-related AEs with TAF (44.1\%) and TDF (48.9\%). The most common drug-related AEs in both groups were nausea (TAF 10.5\%, TDF $13.3 \%$ ), diarrhea (TAF 7.3\%, TDF 8.9\%), and headache (TAF $6.1 \%$, TDF 5.4\%). AEs leading to study drug discontinuation occurred in 11 participants $(1.3 \%)$ on TAF vs $29(3.3 \%)$ on TDF (Table S2 http://links.lww.com/QAI/A986). AEs leading to drug discontinuation in the TAF group occurred predominantly within the first 48 weeks, whereas those in the TDF group continued at a similar frequency through 144 weeks [cumulative events in TAF vs TDF at 48, 96, and 144 weeks: $\mathrm{n}=8$ vs $\mathrm{n}=13(P=0.380) ; 10$ vs $20(P=0.096)$; and 11 vs $29(P=0.006)]$. Incidence of serious AEs was low and similar between groups (TAF 14.0\%, TDF 14.3\%). Serious AEs considered drug related by the investigator occurred in 5 participants $(0.6 \%)$ on TAF (abdominal pain, staphylococcal skin infection, rotator cuff syndrome, erythematous rash, and hypovolemic shock) and 6 participants $(0.7 \%)$ on TDF (spontaneous abortion, immune reconstitution inflammatory syndrome, acute pancreatitis, cholelithiasis, acute coronary syndrome, and drug interaction). Incidence of grade 3 or 4 laboratory abnormalities was similar between groups (TAF $32.9 \%$ vs TDF $30.8 \%$ ); the most common was elevated creatine kinase (TAF $11.5 \%$ vs TDF $10.1 \%$ ).

Participants receiving TAF had significantly smaller declines in total hip and lumbar spine BMD than those receiving TDF through week 144 (\% change from baseline at week 144: hip: TAF $-0.75 \%$, TDF $-3.36 \%$; spine: TAF $-0.92 \%$, TDF $-2.95 \%)(P<0.001)$ (Fig. 2A). More participants on TAF recovered from osteopenia or osteoporosis at either the hip (TAF $\mathrm{n}=14$ vs TDF $\mathrm{n}=10$ ) or spine (TAF $\mathrm{n}=24$ vs TDF $\mathrm{n}=10)$ by week $144(P<0.001$ for difference in distribution of clinical BMD status). Fractures were rare, reported for 6 participants $(0.7 \%)$ on TAF and 16 $(1.8 \%)$ on TDF $(P=0.051)$; all fractures were due to trauma and unrelated to study drug. No discontinuations due to BMD decreases occurred with TAF. Between weeks 48 and 144, 6 men discontinued TDF because of a $>5 \%$ decrease in BMD (ages ranged from 20 to 50 years). At all time points, median percent changes from baseline in serum parathyroid hormone (PTH) were lower with TAF than TDF (week 144: TAF
47.3\%, TDF 71.8\%; $P<0.001$ ) (Fig. 2A). Median values for each group remained within the normal range. Fewer participants on TAF compared with TDF initiated calcium, vitamin $\mathrm{D}$, or other nutritional supplements during the study (16.2\% vs $20.7 \%, P=0.018$ ).

Median change from baseline in creatinine clearance ( $\mathrm{CrCl}$; eGFR by Cockcroft Gault) was significantly lower with TAF $(-1.6 \mathrm{~mL} / \mathrm{min})$ than TDF $(-7.7 \mathrm{~mL} / \mathrm{min})$ at week $144(P<0.001)$ (Fig. 2B). At week 144, significantly fewer participants on TAF $(17.6 \%)$ had a clinically meaningful decrease of $\geq 25 \%$ from baseline in $\mathrm{CrCl}$ compared with TDF (33.4\%) $(P<0.001)$. A quantitative marker of proteinuria (urine protein to creatinine ratio) and specific markers of proximal tubular proteinuria (retinol-binding protein/ $\mathrm{Cr}$ and $\beta$-2-microglobulin/Cr) increased from baseline with TDF, whereas decreases or smaller increases were observed with TAF $(P<0.001)$ (Figs. 2B, C). Fewer participants on TAF developed clinically significant proteinuria (urine protein to creatinine ratio $>200 \mathrm{mg} / \mathrm{g})(\mathrm{n}=22$ vs $40, P=0.016$ for difference in distribution of changes above and below $200 \mathrm{mg} / \mathrm{g})$.

No study drug discontinuations due to renal events occurred with TAF, whereas 12 participants discontinued TDF because of renal-related AEs $(P<0.001)$ (Table S2 http://links.lww.com/QAI/A986): 4 before week 48, 2 between weeks 48 and 96, and 6 after week 96. No cases of proximal tubulopathy occurred in the TAF group, whereas 4 participants receiving TDF had investigatorreported tubulopathy. Seven participants on TDF met laboratory criteria for proximal renal tubulopathy (Tables S3 and S4 http://links.lww.com/QAI/A986), including 4 of the 12 discontinued participants.

There were greater median increases in total cholesterol (TC), high-density lipoprotein (HDL), low-density lipoprotein, and triglycerides in the TAF group compared with the TDF group $(P<0.001)$, whereas there were no differences in the median TC to HDL ratio between groups $(P>0.72$ for weeks 48, 96, and 144) (Fig. 3). There were no differences between TAF and TDF in cardiovascular or cerebrovascular events: 24 participants $(2.8 \%)$ vs $33(3.8 \%)(P=0.28)$, serious cardiovascular or cerebrovascular events: $5(0.6 \%)$ vs $6(0.7 \%)(P=1.00)$, or use of lipid-modifying agents: 48 $(5.5 \%)$ vs $50(5.8 \%)(P=0.92)$.

\section{DISCUSSION}

After 144 weeks of treatment, a TAF-based singletablet regimen maintained a high rate of virologic suppression in treatment-naive participants $(84 \%)$ and met prespecified criteria for both noninferiority and superiority to a TDF-based similar combination, using a priori cutoffs of HIV-1 RNA $<50$ and $<20$ copies/mL. Concordant with this durable high level of suppression was the rare emergence of antiretroviral resistance $(1.4 \%)$.

During this extended period of study, both study regimens continued to be well tolerated. As we have previously reported, the majority of the most common AEs occurred within the first 4 weeks of treatment initiation. ${ }^{18}$ Of note, not only did fewer participants on TAF discontinue 

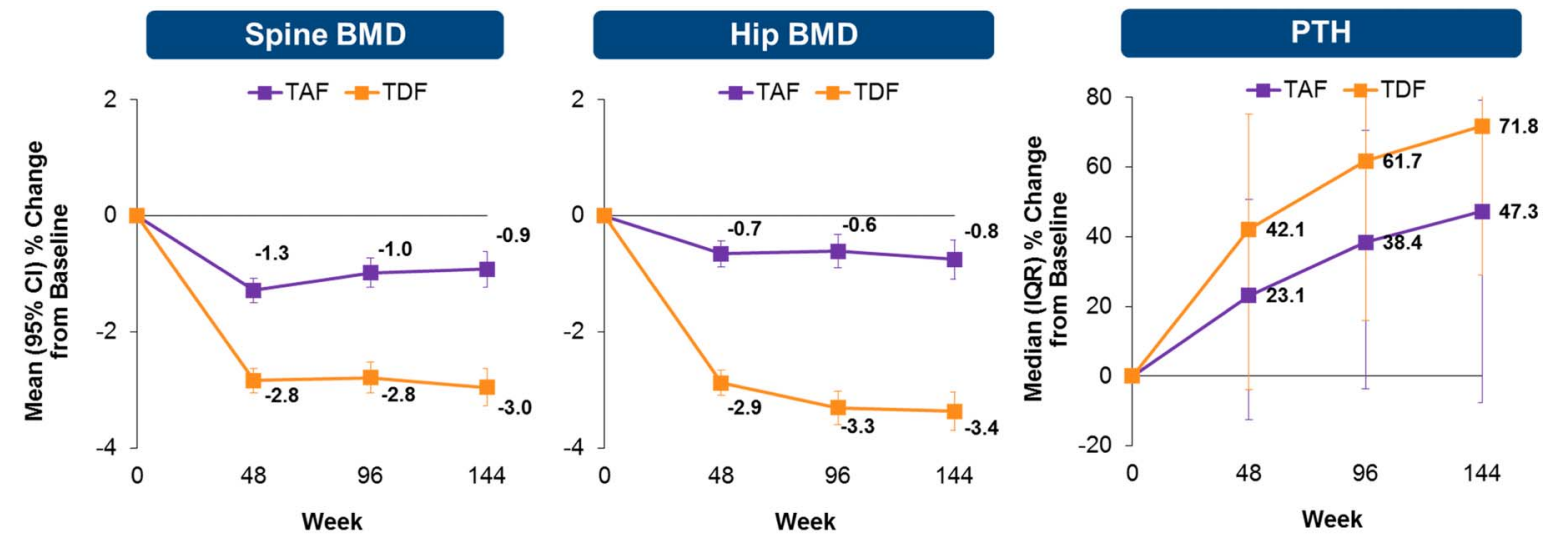

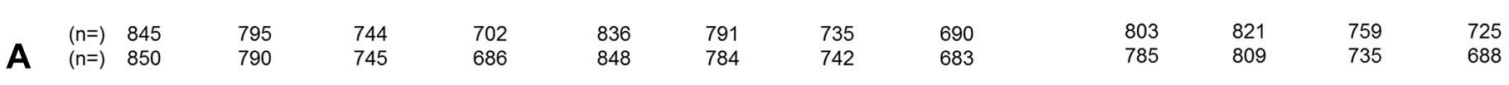
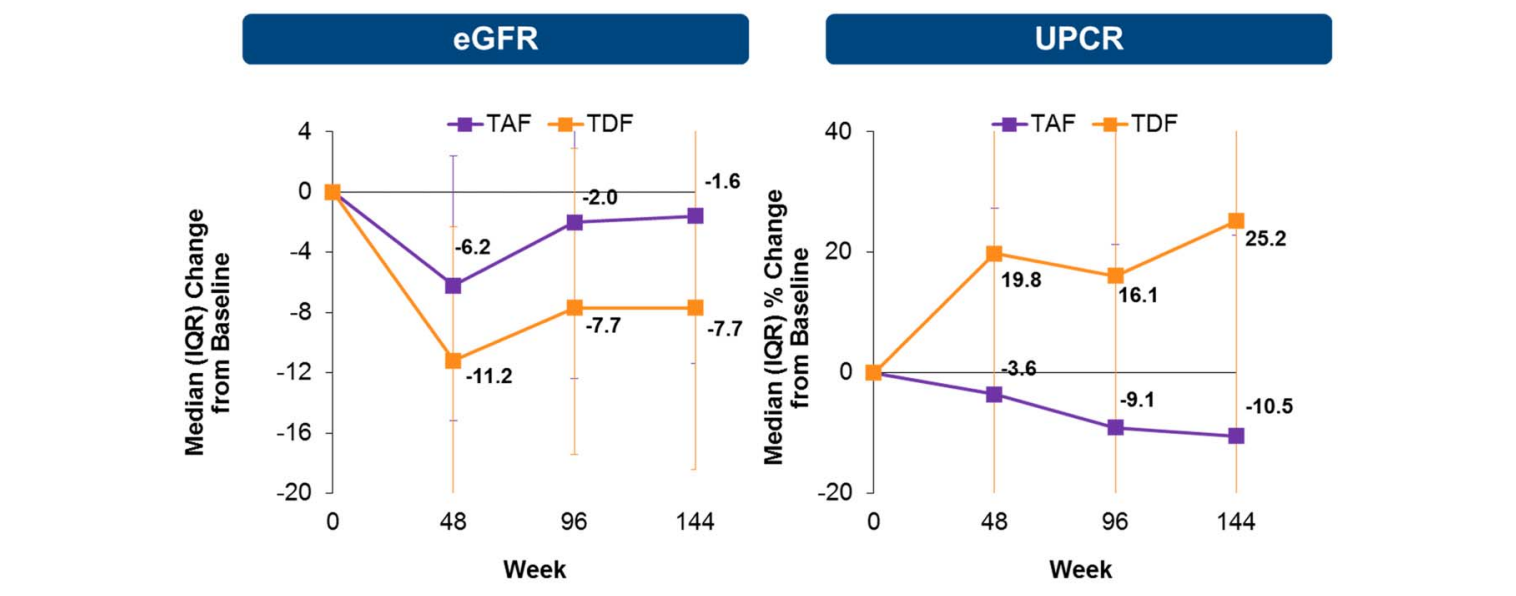

B

$\begin{array}{lllll}(n=) & 866 & 821 & 771 & 740 \\ (n=) & 867 & 806 & 756 & 707\end{array}$

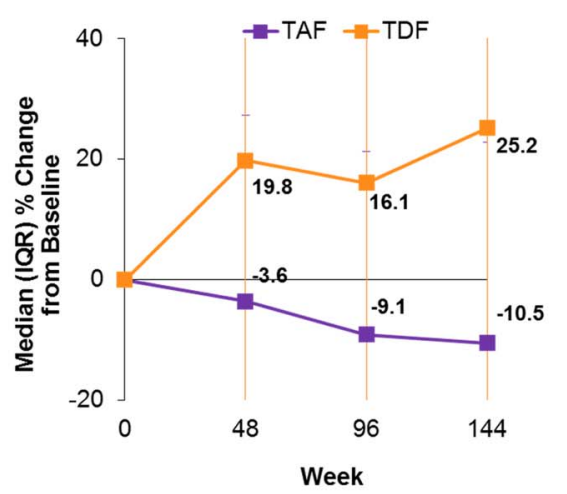

\section{Retinol-Binding Protein: Cr}

ß-2-microglobulin: Cr
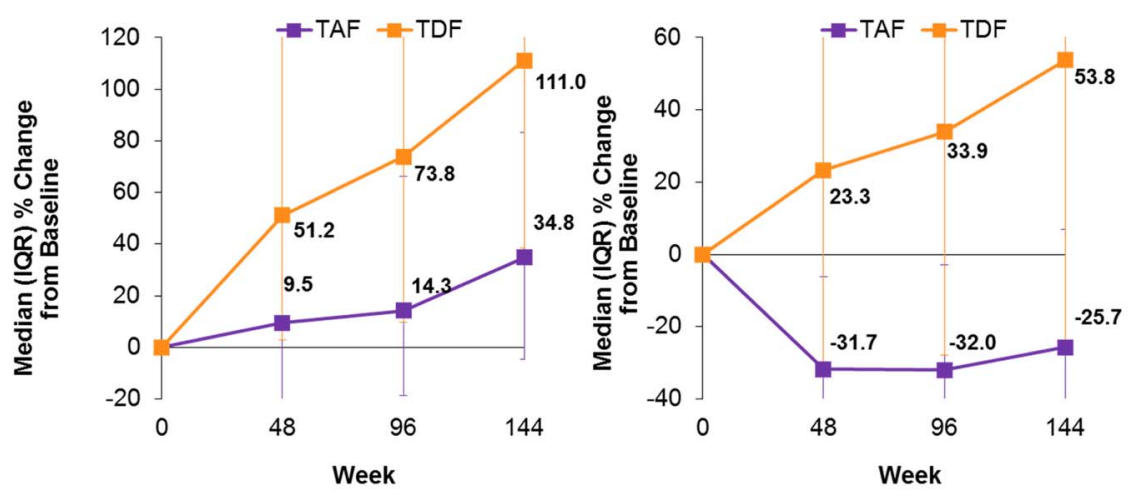

C

$\begin{array}{lllll}(n=) & 855 & 812 & 769 & 728\end{array}$

$\begin{array}{llll}848 & 803 & 761 & 722 \\ 848 & 789 & 737 & 681\end{array}$

FIGURE 2. Key safety endpoints. A, Measures of bone safety: BMD and PTH; (B) Measures of renal safety: eGFR and proteinuria; (C) measures of renal safety: tubular proteinuria. $P<0.001$ for all parameters at all time points. IQR, interquartile range. 


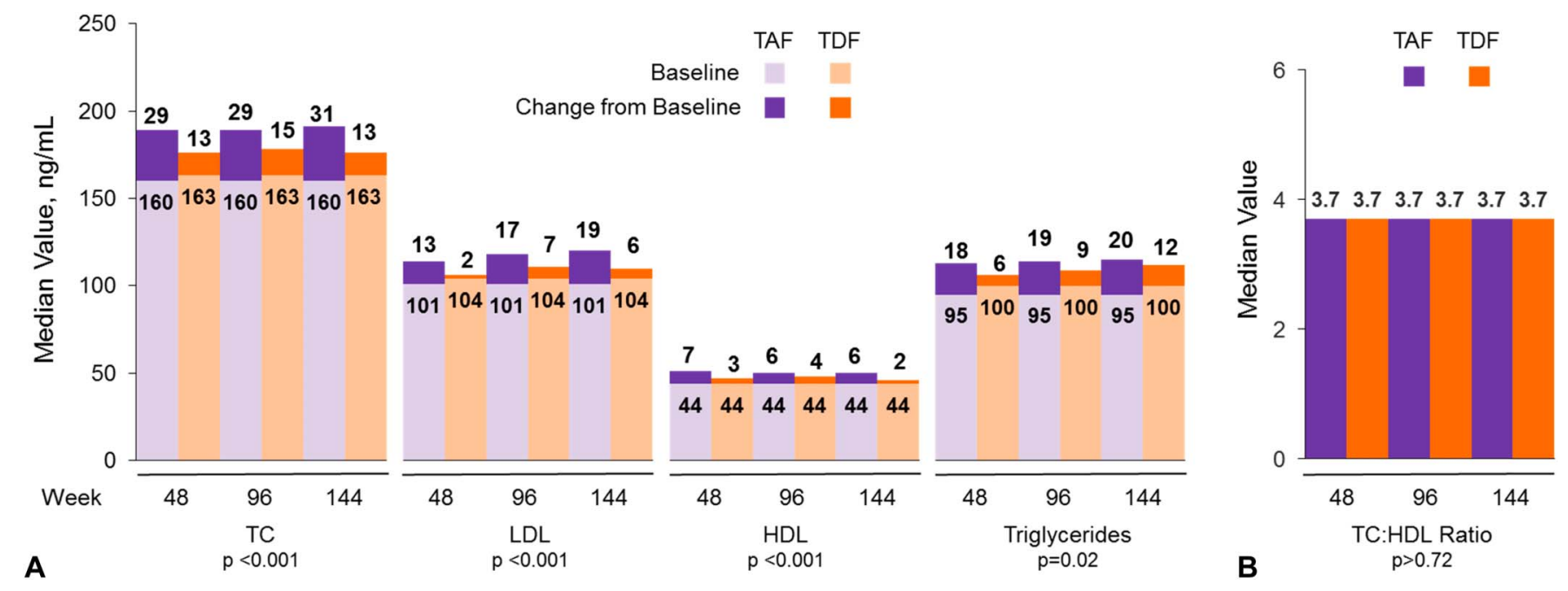

FIGURE 3. Fasting lipid parameters. A, Baseline lipid levels are shown in the lighter color. Increases from baseline are shown in the darker color at each time point. B, Median TC:HDL ratio is shown at each time point.

because of AEs, these AEs leading to discontinuation happened early in the TAF group, whereas those on TDF continued to experience AEs leading to discontinuation steadily through week 144.

Moreover, TAF continued to demonstrate significantly less impact on measures of bone and renal safety than TDF. Through 144 weeks of treatment with TAF, clinical bone and renal AEs in the TAF group were rare. No participants on TAF discontinued study drug because of bone loss, compared with 6 participants on TDF. Significant differences between $\mathrm{TAF}$ and TDF in mean changes from baseline in total hip and lumbar spine BMD observed at week 48 persisted through week 144. Significant differences between groups in median percent changes from baseline in PTH were noted early and through 144 weeks, and the median levels of PTH continued to increase for both groups. However, the median PTH levels stayed within the normal range. The relationship between the observed changes in BMD and PTH is unknown.

Markers of renal function also continued to be more favorable with TAF compared with TDF. A small and rapid decline in $\mathrm{CrCl}$ is expected with administration of cobicistat, which is known to interfere with tubular secretion of creatinine, thereby leading to an increase in serum creatinine and decrease in eGFR without an effect on actual GFR. ${ }^{19}$ In this study, an expected decline in $\mathrm{CrCl}$ was observed in both groups but was more pronounced with TDF, as demonstrated by a significant difference favoring $\mathrm{TAF}$ in percentage of participants who had a $\mathrm{CrCl}$ decline of $\geq 25 \%,{ }^{20}$ a change most likely due to the impact of cobicistat on renal transporters of creatinine. ${ }^{19}$ No participants in the TAF group discontinued because of renal AEs compared with 12 in the TDF group, a statistically significant difference reflecting the lack of TFV-associated nephrotoxicity with TAF.

Proximal renal tubular dysfunction, or tubulopathy, is a rare toxicity associated with TDF and was reported by investigators in 4 participants receiving this agent. With no standardized diagnostic criteria for tubulopathy, an assessment of measures of proximal renal tubular dysfunction was applied to all participants. Tubulopathy was not identified in any participant on TAF. Seven cases identified in the TDF group included 4 of the 12 participants who discontinued treatment because of renal-related AEs. Notably, 1 TDFtaking participant reported to have acquired Fanconi syndrome did not meet the validation criteria. Taken together, these longer-term safety data support the hypothesis that circulating levels of TFV are responsible for bone and renal toxicity with TDF, and markedly reduced TFV levels delivered by TAF minimize such exposure.

Treatment with TDF has consistently been associated with lower lipids compared with other regimens in treatmentnaive or virologically suppressed individuals. ${ }^{21,22}$ This TDF lipid effect is believed to be associated with plasma levels of TFV. ${ }^{21,23,24}$ In this study, participants receiving TAF had greater increases in TC, HDL, low-density lipoprotein, and triglycerides, likely related to significant reductions in plasma TFV concentrations. Changes in fasting lipid levels are most accurately reported not as an adverse effect of TAF but rather as an effect of an absence of high plasma TFV concentrations. Importantly in this study, no treatment differences were observed in the TC:HDL ratios between groups, which is included in cardiovascular risk predictors in the general population such as the Framingham risk and American College of Cardiology/American Heart Association (ACC/ AHA) risk calculators ${ }^{25}$ and associated with the risk for cardiovascular disease in $\mathrm{HIV}$-infected individuals. ${ }^{26} \mathrm{We}$ have previously reported that there is no difference between the TAF vs TDF groups in atherosclerotic cardiovascular disease estimated cardiovascular risk, eligibility for statins, or the incidence of cardiovascular AEs. ${ }^{27}$

Overall, in these large, international, randomized trials following 3 years of treatment, $84 \%$ of those assigned to TAF remained virologically suppressed. TAF was superior to TDF in virologic efficacy and produced significantly more favorable changes in multiple markers of renal and bone health. Despite the increases in lipids in the TAF group, there were no differences between groups in TC:HDL ratio, a predictor 
of cardiovascular risk. These longer-term data support the use of $\mathrm{E} / \mathrm{C} / \mathrm{F} / \mathrm{TAF}$ as a safe, well-tolerated, and durable regimen for initial and ongoing HIV-1 treatment.

\section{STUDY INVESTIGATORS}

C. Achenbach (Northwestern University), F. Ajana (Centre de Hospitalier de Tourcoing Service Maladies Infectieuses et du Voyageur), B. Akil (Chelsea Village Medical), H. Albrecht (University of South Carolina, School of Medicine), J. F. Andrade Villanueva (Hospital Civil de Guadalajara "Fray Antonio Alcalde"), J. Angel (The Ottawa Hospital), A. Antela Lopez (Hospital Clinico Universitario de Santiago, Servicio de Medicina Interna), J. Arribas Lopez (Hospital Universitario La Paz), A. Avihingsanon [The HIV Netherlands Australia Thailand Research Collaboration (HIVNAT)], D. Baker (East Sydney Doctors), J.-G. Baril (Clinique Medicale Du Quartier Latin), D. Bell (Gartnavel General Hospital), N. Bellos (Southwest Infectious Disease Clinical Research Inc), P. Benson (Be Well Medical Center), J. Berenguer (Hospital General Universitario Gregorio Maranon), I. Bica (Boston Medical Center), A. Blaxhult (Venhalsan, Sodersjukhuset), M. Bloch (Holdsworth House Medical Practice), P. Brachman (Atlanta ID Group), I. Brar (Henry Ford Hospital), K. Brinkman (Onze Lieve Vrouwe Gasthuis), C. Brinson (Central Texas Clinical Research), B. Brown (Southwest CARE Center), J. Brunetta (Maple Leaf Research), J. Burack (East Bay AIDS Center), J. Burgos (Hospital Universitario Vall d'Hebron, Servicio de Enfermedades Infecciosas), T. Campbell (University of ColoradoDenver Division of Infectious Diseases), M. Cavassini (CHUV-Service Maladies Infectieuses), A. Cheret (Centre Hospitalier de Tourcoing), P. Chetchotisakd (Khon Kaen University), A. Clarke (Brighton and Sussex University Hospitals NHS Trust), B. Clotet Sala (Hospital Universitario Germans Trias i Pujol), N. Clumeck (CHU St Pierre, Infectious Diseases), C. Cohen (Community Research Initiative of New England), P. Cook (Brody School of Medicine at East Carolina University, Division of Infectious Diseases), L. Cotte (Hôpital de La Croix Rousse), D. Coulston (Premier Clinical Research), M. Crespo Casal (Hospital Universitario Vall d'Hebron, Servicio de Enfermedades Infecciosas), C. Creticos (Howard Brown Health Center), G. Crofoot (The Crofoot Research Center), F. Cruickshank (Rosedale Infectious Diseases), J. Cunha (Servico de Doencas Infecciosas), E. Daar (U Los Angeles Biomedical Research Institute at Harbor-UCLA Medical Center), E. DeJesus (Orlando Immunology Center), J. de Wet (Spectrum Health), M. Doroana (Hospital de Santa Maria), R. Dretler (Infectious Disease Specialists of Atlanta), M. Dube (University of Southern California ACTU), J. Durant (CHU de Nice Archet I, Service d'infectiologie), H. Edelstein (Alameda County Health System-Highland Hospital), R. Elion (Whitman-Walker Clinic), J. Fehr (University Hospital, Zurich), R. Finlayson (Taylor Square Private Clinic), D. Fish (Albany Medical College), J. Flamm (Kaiser Hospital, Sacramento), S. Follansbee (Kaiser Permanente Medical Center, San Francisco), H. Furrer (Universitätsspital Bern), J. Gallant (Southwest CARE Center), F. Garcia (Garcia Family Health Group), J. Gatell
Artigas (Hospital Clinic de Barcelona), J. Gathe (Therapeutic Concepts), S. Gilroy (Albany Medical College), P.-M. Girard (Hôpital Saint Antoine, Service des Maladies infectieuses et Tropicales), J.-C. Goffard (Hôpital Universitaire ErasmeULB), D. Goldstein (Whitman-Walker Health), P. Grant (Stanford AIDS Clinical Trial Unit), R. Grossberg (Montefiore Medical Center), C. Hare (Kaiser Permanente Medical Center, San Francisco), T. Hawkins (Southwest CARE Center), R. Hengel (Atlanta ID Group), W. K. Henry (Hennepin County Medical Center), A. Hite (Summa CARE Center), G. Huhn (Ruth M Rothstein CORE Center), Marc Johnson (Carolinas Medical Center), Margaret Johnson (The Royal Free Hospital, Royal Free Center For HIV Medicine), K. Kasper (Health Sciences Centre Winnipeg), C. Katlama (Groupe Hospitalier Pitié Salpétrière), S. Kiertiburanakul (Ramathibodi Hospital, Mahidol University), J. M. Kilby (Medical University of South Carolina, Division of Infectious Diseases), C. Kinder (AHF Kinder Medical Group), D. Klein (Kaiser Permanente, Division of Infectious Diseases, San Leandro), H. Knobel (Hospital del Mar), E. Koenig (Instituto Dominicano de Estudios Virologicos-IDEV), M. Kozal (Yale University School of Medicine), R. Landovitz (UCLA CARE Center), J. Larioza (Baystate Infectious Diseases Clinical Research), A. Lazzarin (Fondazione San Raffaele del Monte Tabor-Centro San Luigi), R. LeBlanc (Clinique OPUS), B. Lebouché (Chronic Viral Illness Service, Royal Victoria Hospital, McGill University Health Centre), S. Lewis (St Hope Foundation), S. Little (University of California, San Diego), C. Lucasti (South Jersey Infectious Disease), C. Martorell (The Research Institute), C. Mayer (St Joseph's Comprehensive Research Institute), C. McDonald (Tarrant County Infectious Disease Associates), J. McGowan (North Shore University Hospital), M. McKellar (Duke University), G. McLeod (Infectious Diseases Consultants of Greenwich P. C., Greenwich Hospital), A. Mills (Southern California Men's Medical Group), J.-M. Molina (Hopital Saint-Louis Service des Maladies Infectieuses et Tropicales), G. Moyle (Chelsea \& Westminster NHS Trust), M. Mullen (Icahn School of Medicine at Mount Sinai), C. Mussini (Azienda Ospedaliero Universitaria Di Modena Policlinico), C.M. (University of Modena and Reggio Emilia), R. Nahass (ID Care Inc), C. Newman (Georgia Regents Medical Center), S. Oka (National Center for Global Health and Medicine Hospital), H. Olivet (Community Research Initiative of New England), C. Orkin [Grahame Hayton Unit (GHU), Royal London Hospital], P. Ortolani (U.O. Malattie Infettive-Ospedale di Rimini), O. Osiyemi (Triple O Medical Services, PA.), F. Palella (Northwestern University), P. Palmieri (Upstate Infectious Diseases Associates), D. Parks (Central West Clinical Research), A. Petroll (Medical College of Wisconsin, Froedtert Hospital), G. Pialoux (Hopital Tenon), G. Pierone (AIDS Research and Treatment Center of the Treasure Coast), D. Podzamczer (Hospital Universitario de Bellvitge), C. Polk (Infectious Disease Consultants, PA), R. Pollard (University of California, Davis Medical Center), F. Post (King's College Hospital), A. Pozniak (Chelsea \& Westminster NHS Trust), D. Prelutsky (Southampton Healthcare), A. Rachlis (Sunnybrook Health Science Centre), M. Ramgopal (Midway Immunology \& Research Center), B. Rashbaum (Capital 
Medical Associates), W. Ratanasuwan (Department of Preventative and Social Medicine, Siriraj Hospital, Mahidol University), R. Redfield (University of Maryland, Insitiate of Human Virology), G. Reyes Terann (Instituto Nacional de Enfermedades Respiratorias Ismael Cosío Villegas), J. Reynes [University Hospital of Montpellier (CHU-Gui de Chauliac), Département des Maladies Infectieuses et Tropicales], G. Richmond (Gary Richmond, MD, PA), A. Rieger (University of Vienna Medical School), B. Rijnders (Erasmus MC), W. Robbins (Infectious Disease of Central Florida), A. Roberts (Medical Faculty Associates), J. Ross (Whittall Street Clinic), P. Ruane (Peter J. Ruane, MD), R. Rubio Garcia (Hospital Universitario 12 de Octubre), M. Saag (Center to AIDS Research, University of Alabama at Birmingham), J. Santana-Bagur (University of Puerto Rico School of Medicine), L. Santiago (HOPE Clinical Research), J. Saraiva da Cunha (Centro Hospitalar e Universitário de Coimbra EPE), R. Sarmento e Castro (Centro Hospitalar do Porto-Hospital de Santo Antonio), P. E. Sax (Brigham and Women's Hospital), B. Schmied (Otto-Wagner-Spital, Sozialmedizinisches Zentrum Baumgartner Hoehe), T. M. Schmidt (Melbourne Sexual Health Clinic), S. Schrader (Research Access Network), A. Scribner (DCOL Center for Clinical Research), S. Segal-Maurer (New York Presbyterian Queens), B. Sha (Rush University Medical Center, Section of Infectious Diseases), P. Shalit (Peter Shalit, MD), D. Shamblaw (La Playa Medical Group and Clinical Research), C. Shikuma (John A. Burns School of Medicine, University of Hawaii), J. Sims (Saint Hope Foundation Inc), K. Siripassorn (Bamrasnaradura Infectious Diseases Institute), D. Skiest (Baystate Infectious Diseases Clinical Research), J. Slim (Saint Michael's Medical Center), L. Sloan (North Texas Infectious Diseases Consultants), D. Smith (The Albion Centre), K. Squires (Thomas Jefferson University), D. Stein (Jacobi Medical Center), J. Stephens (Mercer University School of Medicine), K. Supparatpinyo (Chiang Mai University), K. Tashima (The Miriam Hospital), S. Taylor (Birmingham Heartlands Hospital), P. Tebas (University of Pennsylvania, Division of Infectious Diseases), E. Teofilo (Centro Hospitalar de Lisboa Central-Hospital Santo Antonio dos Capuchos), A. Thalme (Karolinska Universitetssjukhuset Huddinge), M. Thompson (AIDS Research Consortium of Atlanta), W. Towner (SCPMG/Kaiser Permanente Medical Center-Infectious Diseases, Los Angeles), T. Treadwell (MetroWest Medical Center), B. Trottier (Clinique medicale l'Actuel), T. Vanig (Spectrum Medical Group), N. Vetter (Otto-Wagner-Spital SMZ), P. Viale (Azienda Ospedaliero-Universitaria di Bologna-Policlinico S. OrsolaMalpighi), G. Voskuhl (Trinity Health and Wellness Center/ AIDS Arms, Inc.), B. Wade (AHF-Pensacola), S. Walmsley (University Health Network, Toronto General Hospital Division), D. Ward (Dupont Circle Physicians Group), L. Waters (Mortimer Market Centre, CNWL NHS Foundation Trust), D. Wheeler (Clinical Alliance for Research \& EducationInfectious Diseases, LLC), A. Wilkin (Wake Forest University Health Sciences, Section of Infectious Diseases), T. Wilkin (Presbyterian Hospital Weill Cornell Medical College), E. Wilkins (North Manchester General Hospital, Infectious Disease Research), T. Wills (Hillsborough County
Health Department), D. Wohl (University of North Carolina at Chapel Hill, Division of Infectious Diseases), M. Wohlfeiler (AIDS Healthcare Foundation South Beach), K. Workowski (Emory University, Department of Medicine), D. Wray (Medical University of South Carolina, Division of Infectious Diseases), B. Yangco (Infectious Disease Research Institute), Y. Yazdanpanah (Groupe Hospitalier Bichat Claude Bernard), G.-P. Yeni (Groupe Hospitalier Bichat Claude Bernard), M. Yin (New York Presbyterian Hospital, Columbia University Medical Center), B. Young (Apex Research LLC), A. Zolopa (Stanford AIDS Clinical Trial Unit), and C. Zurawski (Atlanta ID Group, PC).

\section{ACKNOWLEDGMENTS}

The authors thank the participants, their partners and families, and all principal investigators and their study staff for the GS-US-292-0104 and GS-US-292-0111 studies. They also thank Sandra Friborg, Jay Huang, Hui Liu, Caroline Shi, Hui Wang, Michael Miller, Nicolas Margot, and the complete GS-US-292-0104 and GS-US-292-0111 study teams, and Anna Kido (Gilead) for providing editorial assistance.

\section{REFERENCES}

1. Van Rompay KK, Durand-Gasselin L, Brignolo LL, et al. Chronic administration of tenofovir to rhesus macaques from infancy through adulthood and pregnancy: summary of pharmacokinetics and biological and virological effects. Antimicrob Agents Chemother. 2008;52: 3144-3160.

2. Fux CA, Simcock M, Wolbers M, et al. Tenofovir use is associated with a reduction in calculated glomerular filtration rates in the Swiss HIV Cohort Study. Antivir Ther. 2007;12:1165-1173.

3. Goicoechea M, Liu S, Best B, et al. Greater tenofovir-associated renal function decline with protease inhibitor-based versus nonnucleoside reverse-transcriptase inhibitor-based therapy. J Infect Dis. 2008;197: 102-108.

4. Kiser JJ, Carten ML, Aquilante CL, et al. The effect of lopinavir/ritonavir on the renal clearance of tenofovir in HIV-infected patients. Clin Pharmacol Ther. 2008;83:265-272.

5. Hall AM, Hendry BM, Nitsch D, et al. Tenofovir-associated kidney toxicity in HIV-infected patients: a review of the evidence. Am J Kidney Dis. 2011;57:773-780.

6. Sax PE, Wohl D, Yin MT, et al. Tenofovir alafenamide versus tenofovir disoproxil fumarate, coformulated with elvitegravir, cobicistat, and emtricitabine, for initial treatment of HIV-1 infection: two randomised, double-blind, phase 3, non-inferiority trials. Lancet. 2015; 385:2606-2615.

7. Wohl D, Oka S, Clumeck N, et al. Brief report: a randomized, doubleblind comparison of tenofovir alafenamide versus tenofovir disoproxil fumarate, each coformulated with elvitegravir, cobicistat, and emtricitabine for initial HIV-1 treatment: week 96 results. J Acquir Immune Defic Syndr. 2016;72:58-64.

8. Mills A, Arribas JR, Andrade-Villanueva J, et al. Switching from tenofovir disoproxil fumarate to tenofovir alafenamide in antiretroviral regimens for virologically suppressed adults with HIV-1 infection: a randomised, active-controlled, multicentre, open-label, phase 3, noninferiority study. Lancet Infect Dis. 2016;16:43-52.

9. Pozniak A, Arribas JR, Gathe J, et al. Switching to tenofovir alafenamide, coformulated with elvitegravir, cobicistat, and emtricitabine, in HIV-infected patients with renal impairment: 48 week results from a single-arm, multi-center, open-label, phase 3 study. J Acquir Immune Defic Syndr. 2016;71:530-537.

10. Panel on Antiretroviral Guidelines for Adults and Adolescents. Guidelines for the Use of Antiretroviral Agents in HIV-1-infected Adults and Adolescents. Washington, DC: U. S. Department of Health and Human 
Services; 2016. Available at: https://aidsinfo.nih.gov/ContentFiles/ AdultandAdolescentGL.pdf. Accessed August 26, 2016.

11. Günthard HF, Saag MS, Benson CA, et al. Antiretroviral drugs for treatment and prevention of HIV infection in adults: 2016 recommendations of the International Antiviral Society-USA Panel. JAMA. 2016; 316:191-210.

12. AIDS Study Group (GESIDA) of the Spanish Society of Infectious Diseases, Clinical Microbiology, the National AIDS Plan. Executive summary of the GESIDA/National AIDS Plan Consensus Document on Antiretroviral Therapy in Adults Infected by the Human Immunodeficiency Virus (Updated January 2016). Enferm Infecc Microbiol Clin. 2016;34:439-451.

13. Ministry of Health, National Committee on AIDS-Commissione Nazionale per la lotta contro l'AIDS. Linee Guida Italiane sull'utilizzo dei farmaci antiretrovirali e sulla gestione diagnosticoclinica delle persone con infezione da HIV-1 [in Italian]. Rome, Italy: Ministero della Salute; 2015. Available at: http://www.salute.gov.it/imgs/C_17_ pubblicazioni_2442_allegato.pdf. Accessed April 15, 2016.

14. Danish Society of Infectious Diseases. Antiviral behandling af HIV smittede personer, Odense C, DK. August 2015 [in Danish]. Available at: http://www.infmed.dk/guidelines. Accessed April 15, 2016.

15. Snopková $\mathrm{S}$, Rozsypal $\mathrm{H}$, Aster $\mathrm{V}$, et al. Doporučený postup péče o dospělé infikované HIV a postexpoziční profylaxe infekce HIV [in Czech]. Klin Mikrobiol Infekc Lek. 2016;22:20-38.

16. DAIG | Deutsche AIDS-Gesellschaft e.V. Deutsch-Österreichische Leitlinien zur antiretroviralen Therapie der HIV-Infektion, Version 6 [in German]. Hamburg, DE: DAIG; 2015. Available at: http://www.daignet. de/site-content/hiv-therapie/leitlinien-1. Accessed April 15, 2016.

17. Smith F, Hammerstorm T, Soon G, et al. A meta-analysis to assess the FDA DAVP's TLOVR algorithm in HIV submissions. Drug Inf J. 2011; 45:291-300.

18. Segal-Maurer S, Henry K, Benson P, et al. Common adverse drug reactions of elvitegravir, cobicistat, and emtricitabine co-formulated with tenofovir alafenamide or tenofovir disoproxil fumarate. Presented at the 18th International Workshop on Co-morbidities and Adverse Drug Reactions in HIV; September 12-13, 2016; New York, NY. Poster \#P19.
19. German P, Liu HC, Szwarcberg J, et al. Effect of cobicistat on glomerular filtration rate in subjects with normal and impaired renal function. J Acquir Immune Defic Syndr. 2012;61:32-40.

20. Lopes JA, Jorge S. The RIFLE and AKIN classifications for acute kidney injury: a critical and comprehensive review. Clin Kidney J. 2013;6:8-14.

21. Tungsiripat M, Kitch D, Glesby MJ, et al. A pilot study to determine the impact on dyslipidemia of adding tenofovir to stable background antiretroviral therapy: ACTG 5206. AIDS. 2010;24:1781-1784.

22. Santos JR, Saumoy M, Curran A, et al. The lipid-lowering effect of tenofovir/emtricitabine: a randomized, crossover, double-blind, placebocontrolled trial. Clin Infect Dis. 2015;61:403-408.

23. Behrens G, Maserati R, Rieger A, et al. Switching to tenofovir/ emtricitabine from abacavir/lamivudine in HIV-infected adults with raised cholesterol: effect on lipid profiles. Antivir Ther. 2012;17: 1011-1020.

24. Mulligan K, Glidden DV, Anderson PL, et al. Decreases in cholesterol in HIV-seronegative men using emtricitabine/tenofovir pre-exposure prophylaxis: lipid results of iPrEx. Presented at the 15th International Workshop on Co-morbidities and Adverse Drug Reactions in HIV; October 15-17, 2013; Brussels, Belgium. Available at: http://www.intmedpress.com/serveFile.cfm? sUID=bc75b62c-c206-437a-b725-a75baa67f5b2. Accessed September 13, 2016.

25. Goff DC, Lloyd-Jones DM, Bennett G, et al. 2013 ACC/AHA guideline on the assessment of cardiovascular risk: a report of the American College of Cardiology/American Heart Association Task Force on Practice Guidelines. Circulation. 2014;129:S49-S73.

26. Friis-Møller N, Ryom L, Smith C, et al. An updated prediction model of the global risk of cardiovascular disease in HIV-positive persons: the data-collection on adverse effects of anti-HIV drugs (D:A:D) study. Eur J Prev Cardiol. 2016;23:214-223.

27. Huhn G, Shamblaw D, Baril JG, et al. Atherosclerotic CVD risk profile of tenofovir alafenamide (TAF) vs tenofovir disoproxil fumarate. Presented at the 18th International Workshop on Co-morbidities and Adverse Drug Reactions in HIV; September 12-13, 2016; New York, NY. Available at: http://www.natap.org/2016/AGE/AGE_17.htm. Accessed December 16, 2016. 